\title{
Maternal and child nutrition in Sub-Saharan Africa: challenges and interventions
}

\author{
Anna Lartey* \\ Department of Nutrition and Food Science, University of Ghana, Legon, Ghana
}

\begin{abstract}
Women of child-bearing age (especially pregnant and lactating women), infants and young children are in the most nutritionally-vulnerable stages of the life cycle. Maternal malnutrition is a major predisposing factor for morbidity and mortality among African women. The causes include inadequate food intake, poor nutritional quality of diets, frequent infections and short inter-pregnancy intervals. Evidence for maternal malnutrition is provided by the fact that between 5 and $20 \%$ of African women have a low BMI as a result of chronic hunger. Across the continent the prevalence of anaemia ranges from 21 to $80 \%$, with similarly high values for both vitamin A and $\mathrm{Zn}$ deficiency levels. Another challenge is the high rates of HIV infection, which compromise maternal nutritional status. The consequences of poor maternal nutritional status are reflected in low pregnancy weight gain and high infant and maternal morbidity and mortality. Suboptimal infant feeding practices, poor quality of complementary foods, frequent infections and micronutrient deficiencies have largely contributed to the high mortality among infants and young children in the region. Feeding children whose mothers are infected with HIV continues to remain an issue requiring urgent attention. There are successful interventions to improve the nutrition of mothers, infants and young children, which will be addressed. Interventions to improve the nutrition of infants and young children, particularly in relation to the improvement of micronutrient intakes of young children, will be discussed. The recent release by WHO of new international growth standards for assessing the growth and nutritional status of children provides the tool for early detection of growth faltering and for appropriate intervention.
\end{abstract}

Pregnant and lactating women: Maternal malnutrition: HIV-infected mothers: Intervention

Women, especially pregnant and lactating women, infants and young children are among the most nutritionallyvulnerable groups. Their nutritional vulnerability stems from their physiologically-higher nutrient requirements, which are often not met ${ }^{(1,2)}$. Pregnancy and lactation places additional demands on women. Similarly, for infants rapid growth and development results in an increase in nutrient requirements $^{(3)}$.

For women and children in Sub-Saharan Africa the environmental and economic conditions place an extra burden on their nutritional status ${ }^{(2)}$. Pervasive poverty affects the quality of the diet ${ }^{(4)}$. The heavy workload of women increases their nutritional requirements ${ }^{(5)}$. Frequent and short reproductive cycles often leave the African woman moving from one pregnancy to the next without adequately repleting body nutrient stores $^{(6)}$. Infants and young children suffer frequent infections and have poor-quality diets ${ }^{(7)}$. These factors create an ideal environment for malnutrition to thrive. Malnutrition further predisposes African women and children to morbidity and mortality.

The objective of the present paper is to discuss the nutritional challenges faced by women and children in Sub-Saharan Africa and to highlight successful interventions to address these challenges.

\section{Issues of maternal nutrition}

The consequences of maternal malnutrition have both short- and long-term implications for the mother and her offspring.

Fig. 1 summarises the nutritional factors that often result in maternal malnutrition and the consequences for the 


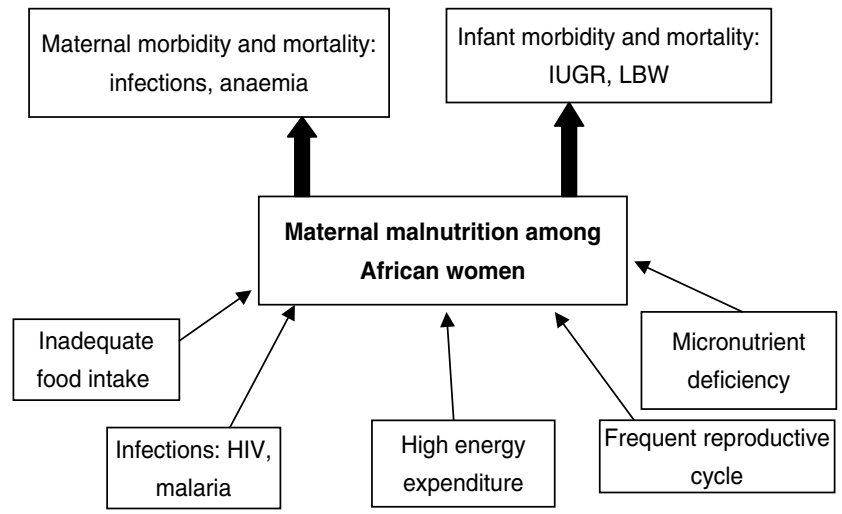

Fig. 1. Effect of maternal malnutrition on maternal and infant health. IGUR, intrauterine growth restriction; LBW, low birth weight.

mother and infant. The widespread malnutrition among African women is manifested by the low maternal BMI $\left(<18.5 \mathrm{~kg} / \mathrm{m}^{2}\right)$ for $\leq 20 \%$ of African women of reproductive age ${ }^{(6)}$. Consequently, maternal pregnancy weight gain is low ${ }^{(6)}$.

Inadequate pregnancy weight gain is reflected in the high prevalence of low birth weight among $14 \%$ of infants in Sub-Saharan Africa ${ }^{(8)}$. Although pregnancy is considered a normal physiological event in the life cycle, for most African women it is a life-threatening situation ${ }^{(9)}$. The probability of dying from pregnancy-related causes is one in sixteen for Sub-Saharan Africa compared with one in 4000 for industrialised countries ${ }^{(8)}$. About $40 \%$ of women aged 20-24 years in Sub-Saharan Africa marry early (at $<18$ years of age) ${ }^{(8)}$. With many years of child bearing ahead, pregnancies occur frequently and at short intervals, giving the mother insufficient time to replenish her nutrient stores before the next pregnancy ${ }^{(6)}$. The poor quality of the diet contributes to the widespread energy and micronutrient deficiencies ${ }^{(5)}$.

HIV infection has worsened the nutritional profile of African women. About 13.1 million African women aged 15-49 years live with HIV/AIDS ${ }^{(8)}$, which coupled with poor nutritional status quickly precipitates maternal malnutrition ${ }^{(6)}$. Maternal malnutritional status during pregnancy sets the stage for poor pregnancy outcomes, affecting the survival and quality of life for the offspring $^{(10)}$.

\section{Issues for infant and young children}

For the developing fetus, its first battle is to survive the intrauterine environment ${ }^{(11)}$. For those who survive there are several challenges that must be surmounted postnatally. The battle to survive through the first year of life is a tough one for the African child. Indeed, global statistics indicate that the infant mortality of 102 per 1000 live births for Sub-Saharan Africa ${ }^{(8)}$ is the highest for all regions. Early childhood malnutrition most probably accounts for the high prevalence of stunting (38\%) and underweight (28\%) reported for children $<5$ years of age in Sub-Saharan Africa $^{(8)}$.

\section{Infant feeding practices}

Although evidence of the life-saving benefits of exclusive breast-feeding up to 6 months of age is compelling ${ }^{(12)}$, only $30 \%$ of children $<6$ months of age in Sub-Saharan Africa are exclusively breast-fed ${ }^{(8)}$. As a result of suboptimal feeding practices the complementary feeding period presents a great threat to the survival of the African child $^{(7)}$. Complementary foods are mainly watery cereal porridges of low energy and nutrient densities ${ }^{(13)}$, and they are often prepared, served and stored under conditions that expose the child to frequent infections ${ }^{(14)}$.

Older infants and young children are not often given the care and attention needed for the selection of nutritious foods and the encouragement needed to eat foods in sufficient amounts to meet their energy and nutrient requirements ${ }^{(15)}$.

The advent of HIV/AIDS has been an obstacle to the efforts to improve child nutritional status ${ }^{(16)}$. The feeding of infants and young children whose mothers are infected with HIV continues to be a challenge. Safe infant feeding options are still problematic ${ }^{(17)}$.

\section{Interventions to improve maternal and child nutrition}

\section{Improving maternal nutritional status}

As maternal malnutrition has intergenerational effects, the nutrition of women must be addressed very early in life ${ }^{(6)}$. Special emphasis must be placed on improving the nutrition of adolescent girls, who are at the dawn of adulthood (taking on reproductive roles). The nutritional demands of pregnancy place adolescent girls at high risk of maternal mortality, pregnancy-related complications and the delivery of low-birth-weight infants ${ }^{18)}$. Addressing the nutritional needs of adolescent girls prepares them to move into adulthood ready to take on reproductive roles. Women must have an adequate nutritional status before and during pregnancy to provide a good intrauterine environment for the developing fetus ${ }^{(19)}$.

Many countries in Sub-Saharan Africa have instituted supplementary feeding programmes to improve the nutritional status of schoolchildren. The window of opportunity to make a difference for nutrition should start prenatally ${ }^{(20)}$. Thus, supplementary feeding programmes for pregnant and lactating women in countries with high rates of maternal malnutrition should also be considered. Antenatal and postnatal centres provide a captive audience for such programmes. Maternal nutrition education should be a strong component of antenatal and postnatal care and should emphasise the use of fortified staples, animal-source foods, dietary diversification and the use of supplements to improve the quality of $\operatorname{diet}^{(21)}$. With this approach, early and regular antenatal attendance would ensure that women would benefit fully from micronutrient supplements and other nutrition interventions.

Mothers should have ready access to skilled medical attendants at delivery. Data from UNICEF indicate that only $42 \%$ of births in Sub-Saharan Africa are attended by skilled health personnel ${ }^{(8)}$. 


\section{Sustaining exclusive breast-feeding}

Promotion of exclusive breast-feeding is ranked as the most effective intervention for reducing the mortality of $<5$ year-olds ${ }^{(22)}$. Access to this knowledge does not necessarily increase exclusive breast-feeding rates. Consistent and concerted efforts are needed to ensure exclusive breast-feeding to 6 months of age. A community-based randomised intervention study in Ghana has assessed the effect of lactation counselling on exclusive-breast-feeding rates among Ghanaian mothers ${ }^{(23)}$. The results show a $100 \%$ increase in exclusive-breast-feeding rates among mothers that received exclusive-breast-feeding support compared with the control group that only received health education information without breast-feeding support. The effectiveness of incorporating breast-feeding counselling within the healthcare system has been well recognised in the WHO-UNICEF Baby Friendly Hospital Initiative ${ }^{(24)}$. However, for sustained impact support must move beyond the hospital environment into the communities where mothers face the biggest challenge to continue with the practice.

\section{Improving complementary feeding practices}

Growth faltering is often widespread during the complementary feeding period, an indication of the suboptimal complementary feeding practices ${ }^{(25)}$. Considerable global and national efforts and attention have been devoted to breast-feeding promotion to the neglect of complementary feeding practices. As pointed out by Lutter "infant and young child nutrition will improve only if improvements in complementary feeding are combined with improvement in breastfeeding, environmental sanitation and health ${ }^{\text {(26) }}$.

Interventions using local technologies such as roasting, malting, drying, fermentation and grinding to process locally-available ingredients are likely to be more successful ${ }^{(27)}$. To this end, the uses of multimixes of cereal legumes have been extensively explored and studied $^{(28-30)}$.

Sub-Saharan Africa abounds in a variety of indigenous and traditional foods that can be drawn upon to improve the quality of complementary foods through dietary diversification. However, lack of information on the nutritional composition of local indigenous and traditional foods limits their use ${ }^{(31)}$.

Meeting the micronutrient requirements of infant and young children is a challenge, because of their high nutrient requirement and small stomach capacity ${ }^{(3,13,32)}$. Fortification of staple foods does not address their micronutrient needs ${ }^{(3)}$. Direct fortification of commercial complementary foods is more effective ${ }^{(33)}$. However, cost and affordability remain an issue for poor households ${ }^{(34)}$. Direct addition of micronutrients, as sprinkles powder, crushable nutritabs tablets or nutributter, to home-prepared complementary foods is gaining ground as a useful strategy for improving the micronutrient quality of children's $\operatorname{diet}^{(35)}$, as it does not require the caregiver to prepare new foods.

\section{Nutrition education}

Nutrition education for caregivers on child feeding practices has the potential to improve child nutritional status. Nutrition education that provides simple messages tailored for low-income families has made an impact on caregiver child feeding practices, and subsequently on child growth ${ }^{(36)}$. Studies using the positive deviant approach have shown that in the midst of poverty good caregiver practices can substantially improve growth for children in both urban ${ }^{(37)}$ and rural ${ }^{(15)}$ settings. Nutrition education must be made an integral part of the health delivery system.

Attempts to improve infant and child nutrition must be linked to regular growth monitoring and intervention. The WHO child growth standards ${ }^{(38)}$ provide the tool to assess and advocate for appropriate infant and young child feeding and good care practices for improved growth.

\section{Conclusions}

There are serious issues relating to maternal and child nutrition that often result in unacceptably-high morbidity and mortality rates in Sub-Saharan Africa. The interventions needed to make a difference are known. What is needed is to scale up these successful interventions to levels that would make an impact. A country that seeks to tap the full potential of its human resource cannot afford to neglect the nutrition of its citizens, especially the nutrition of women and children. This process requires resources and commitment. For every child a delay of $1 \mathrm{~d}$ in intervening is a missed opportunity to make a difference.

\section{References}

1. Daelmans B \& Saadeh R (2003) Global initiative to improve complementary feeding. SCN News 27, 10-18.

2. Prentice A (1993) Nutritional requirements for growth, pregnancy and lactation: the Keneba experience. S Afr J Clin Nutr 6, 33-38.

3. Dewey KG (2003) Nutrient composition of fortified complementary foods: should age-specific micronutrient content and ration sizes be recommended. J Nutr 133, 2950S-2952S.

4. World Bank (1998) Nutritional Status and Poverty in SubSaharan Africa. Findings no. 108. Washington, DC: World Bank; available at http://www.worldbank.org/afr/findings/ english/find108.htm.

5. Prentice AM, Whitehead RG, Watkinson M, Lamb WH \& Cole TJ (1983) Prenatal dietary supplementation of African women and birth weight. Lancet 5, 489-491.

6. Linkages Project (2001) Essential Health Sector Actions to Improve Maternal Nutrition in Africa. Washington, DC: Academy for Educational Development.

7. Onofiok NO \& Nnanyelugo DO (1998) Weaning foods in West Africa: nutritional problems and possible solutions. Food Nutr Bull 19, 17-20.

8. UNICEF (2005) The State of the World's Children 2006 Excluded and Invisible. New York: UNICEF.

9. Abdoulae D (2006) Maternal mortality in Africa. Internet $J$ Health 5; available at http://www.ispub.com/ostia/index.php? $\mathrm{xmlFilePath=journals/ijh/vol5n1/africa.xml}$ 
10. Shrimpton R (2006) Life cycle and gender perspectives on the double burden of malnutrition and the prevention of diet related chronic diseases. SCN News 33, 11-14.

11. United Nations ACC/SCN (2000) Fourth Report on the World Nutrition Situation. Nutrition Throughout the Life Cycle. Geneva: ACC/SCN and IFPRI; available at http:// www.ifpri.org/pubs/books/4thrpt/4threport.pdf

12. World Health Organization (2002) The Optimal Duration of Exclusive Breastfeeding: A Systematic Review. Geneva: WHO.

13. Gibson RS, Ferguson EL \& Lehrfeld J (1998) Complementary foods for infant feeding in developing countries: their nutrient adequacy and improvement. Eur J Clin Nutr 52, 764-770.

14. Kimmons JE, Brown KH, Lartey A, Collision E, Mensah PA \& Dewey KG (1999) The effects of fermentation and/or vacuum flask storage on the presence of coliforms in complementary foods prepared for Ghanaian children. Int J Food Sci Nutr 150, 195-201.

15. Nti A \& Lartey A (2007) Effect of caregiver feeding behaviours on child nutritional status in rural Ghana. Int J Consum Stud 31, 303-309.

16. Nduati R, John G, Mbori-Ngacha D et al. (2002) Effect of breastfeeding and formula feeding on transmission of HIV -1: A randomized clinical trial. J Am Med Assoc 283, 1167-1174.

17. Leshabari SC, Blystad A, de Paoli M \& Moland KM (2007) HIV and infant feeding counseling: challenges faced by nurse-counsellors in northern Tanzania. Human Resour Health 5, 18.

18. Kurtz KM, Barua A, Khate B \& Prasad J (2006) Delaying age of marriage and meeting reproductive health needs of married adolescent women. SCN News 31, 24-29.

19. Rush D (2000) Nutrition and maternal mortality in the developing world. Am J Clin Nutr 72, 212S-240S.

20. World Bank (2006) Repositioning Nutrition as Central to Development. A Strategy for Large Scale Action. Washington DC: World Bank.

21. Gross R (editor) (1999) Micronutrient supplementation throughout the life cycle. Report of a workshop held by the Ministry of Health, Brazil and UNICEF. http://www.idpas. org/pdf/752MicronutSuppLife.pdf

22. Jones G, Steketee RW \& Black RE (2003) How many child deaths can we prevent this year? Lancet 362, 65-71.

23. Aidam BA, Perez-Escamilla R \& Lartey A (2005) Lactation counselling increases exclusive breast-feeding rates in Ghana. J Nutr 135, 1691-1695.

24. World Health Organization (1989) Protecting, Promoting and Supporting Breastfeeding: The Special Role of Maternity Services. Geneva: WHO.

25. Dewey KG, Peerson JM, Heinig MJ, Nommsen LA, Lonnerdal B, Lopez de Romana G, de Kanashiro HC, Black RE \& Brown KH (1999) Growth patterns of breastfed infants in affluent (United States) and poor (Peru) communities: Implications for timing of complementary feeding. Am J Clin Nutr 56, 1012-1018.

26. Lutter C (2003) Meeting the challenges to improve complementary feeding. SCN News 27, 4-9.

27. Mensah P \& Tomkins A (2003) Household-level technologies to improve the availability and preparation of adequate and safe complementary foods. Food Nutr Bull 24, 104-125.

28. Amuna P, Zotor F, Chinyanga YT \& Chinyanga YT (2000) The role of traditional cereal/legume/fruit-based multimixes in weaning in developing countries. Nutr Food Sci 30, 116122.

29. Amuna P, Zotor F \& Tewfik I (2004) Human and economic development in developing countries: a public health dimension employing the food multimix concept. World Rev Sci Technol Sustain Dev 1, 129-137.

30. Lartey A, Manu A, Brown KH, Peerson JM \& Dewey KG (1999) A randomized, community-based trial of the effects of improved, centrally processed complementary foods on growth and micronutrient status of Ghanaian infants from 6-12 mo of age. Am J Clin Nutr 70, 391-404.

31. Smith IF, Eyzaguirre PB, Matig OE \& Johns T (2006) Managing biodiversity for food and nutrition security in West Africa: building on indigenous knowledge for more sustainable livelihoods. SCN News 33, 22-26.

32. World Health Organization (1998) Complementary Feeding of Young Children in Developing Countries: A Review of Current Scientific Knowledge. Geneva: WHO.

33. Zlotkin SH, Christofides AL, Hyder SM, Schauer CS, Tondeur MC \& Sharieff W (2004) Controlling iron deficiency anemia through the use of home fortified complementary foods. Indian J Pediatr 71, 1015-1019.

34. Nesamvuni AE, Vorster HH, Margetts BM \& Kruger A (2005) Fortification of maize meal improves the nutritional status of 1-3 year old African children. Public Health Nutr 8, 461-467.

35. Adu-Afarwuah S, Lartey A, Brown $\mathrm{KH}$, Zlotkin S, Briend A \& Dewey KG (2007) Randomized comparison of 3 types of micronutrient supplements for home fortification of complementary foods in Ghana: effects on growth and motor development. Am J Clin Nutr 86, 412-420.

36. Penny ME, Creed-Kanashiro HM, Robert RC, Narro M, Caulfield L \& Black R (2005) Effectiveness of an educational intervention delivered through the health services to improve your child nutrition: A cluster-randomised controlled trial. Lancet 365, 1863-1872.

37. Ruel MT, Pelletier DL, Habicht JP, Mason JB, Chobokoane CS \& Maruping AP (1990) Comparison of mothers understanding of two child growth charts in Lesotho. Bull World Health Organ 68, 483-491.

38. WHO Multicenter Growth Reference Study Group (2006) WHO Child Growth Standards based on length/height, weight and age. Acta Paediatrica Suppl 450, 76-85. 